\title{
Construindo fantasias
}

\section{Building fantasies}

DOI: $10.54018 /$ sssrv2n3-004

Recebimento dos originais: 05/07/2021

Aceitação para publicação: 20/08/2021

\section{Neusa Cavalcante \\ Universidade de Brasília - UnB \\ E-mail: neusa.cavalcante@gmail.com \\ Eliel Américo Santana da Silva \\ Universidade de Brasília - UnB \\ E-mail: americoeliel@gmail.com \\ Márcia Urbano Troncoso \\ Universidade de Brasília - UnB \\ E-mail: marciaurbanotroncoso@gmail.com}

\section{RESUMO}

Oferecida para recém ingressos na universidade, a disciplina Geometria Construtiva, desenvolve-se, em um ambiente experimental, por meio de uma série de exercícios e aulas expositivas e de repertório sobre artes visuais e abstração. O primeiro insight recai sobre a natureza, fonte para ampliação da acuidade tátilvisual. Do desenho de observação (imitação), parte-se para a interpretação e abstração (criação), que objetiva o desnudamento dos padrões ocultos nos "objetos ' da natureza. "Tornar visível o invisível" constitui um caminho necessário aos arquitetos, cujo principal desafio está no "jogo sábio, correto e magnífico" das formas abstratas. Avança-se então em direção à síntese, bastando, em seguida, uma sensibilização sobre características/propriedades dos materiais para que as criações bi e tridimensionais se realizem como arte (construção) ou, segundo Davidovici, como "formas esperando para ser arquitetura". Com um repertório mais consolidado, pode-se encarar novas aventuras. A dança, ocirco, o carnaval, o brinquedo, e As Cidades Invisíveis (1972), de Italo Calvino, tornam-se pretextos para exercícios mais libertos. Surgem então as fantasias... cujo ato criativo pressupõe um espírito lúdico que usa a abstração como ferramenta para construção de utopias. Lúdico, abstração e utopia implicam a ruptura de limites: o lúdico enquanto extrapolação da realidade cotidiana, a abstração como exercício de ampliação da capacidade visual e a utopia como enfraquecimento das fronteiras entre razão e imaginação.

Palavras-chave: Natureza. Geometria. Abstração. Construção. Arte. Fantasia.

\section{ABSTRACT}

Offered for the new university students, the discipline Geometria Construtiva develops itself in anexperimental way, through a series of exercises, conceptual 
lectures and repertoire classes on visual arts and abstraction process. The first insight refers to nature itself, a source for expansion of tactile-visual perception. From drawing (imitation), it follows to interpretation and abstraction (creation), which aims the discovery of hidden patterns of nature's 'objects'. "To make visible theinvisible" is a necessary path to architects, whose main challenge is "the wise, correct and magnificent game" of abstract forms. Then it advances toward synthesis and, after a consciousness of characteristics/properties of materials, two and three-dimensional creations aretransformed into pieces of art (construction) or, according to Davidovici, into "shapes waiting to be architecture". With a more consolidated repertoire, new adventures can be faced. Dances, circus, carnival, toys, and also The Invisible Cities (1972), of Italo Calvino, are pretexts for freer exercises. Then come out the fantasies ... whose creation presupposes the playfulness that usesabstraction as a tool for building utopias. Ludic, abstraction and utopia imply a break of boundaries: Iudic as an extrapolation of everyday reality, abstraction as an enlargement of visualcapacity and utopia as a way to weaken the limits between reason and imagination.

Keywords: Nature. Geometry. Abstraction. Construction. Art. Fantasies

\section{INTRODUÇÃO}

O presente artigo procura explorar uma atividade de ensino que, desenvolvida na FAU-UnB há 18 anos, constitui um resgate de experiências realizadas, por volta de 1960, porAthos Bulcão, no antigo Instituto Central de Artes (ICA-UnB) e Caetano Fraccaroli, na FAUSP; e continuada, posteriormente, por Jayme Golubov, na FAU-UnB. A disciplina Geometria Construtiva desenvolve-se em um ambiente experimental, por meio de umasérie de exercícios, apoiados por aulas conceituais e de repertório sobre arte abstrata eprocesso de abstração.

O primeiro insight recai sobre a natureza enquanto fonte para ampliação da acuidade tátil-visual. Da análise da natureza - por meio do desenho de seus 'objetos' (arte comoimitação), avança-se em direção à interpretação e à abstração (arte como criação). Emseguida, parte-se para a síntese (arte como construção), que traz em si as técnicas necessárias à materialização do ato criador. E basta uma sensibilização sobre as características e propriedades dos materiais para que as criações, bi e tridimensionais, se realizem como objetos de arte.

Com um repertório mais consolidado, parte-se para outras aventuras. Diversas manifestações culturais tornam-se pretextos para exercícios mais libertos. Surgem então as fantasias... que, dando vazão ao lúdico e à capacidade de abstração, ampliamos limites do nosso espaço vital. 


\section{ESTABELECENDO PONTESENTRE NATUREZA EARQUITETURA}

[...] se Deus pôde permitir-se um sétimo dia de repouso, foi porque o homem assumiu a honra de prosseguir a criação incompleta [...] o homem, único animal que não descansa nunca, continua na sua frenética atividade de descoberta e invenção, de criação e procriação [...] seis bilhões de cérebros adormecem e começam a sonhar formas [...] acordam e começam a pensar em como traduzir na prática esses sonhos. (Domenico de Mais)

O grande livro, sempre aberto e que convém esforçarmo-nos para ler, é o da Natureza; todos os demais surgiram deste e têm, para além do mais, as interpretações e equívocos dos homens [...] Se a natureza é um feito do Criador e as formas arquiteturais derivam da natureza, isto significa que o Criador está sendo continuado.(Antoni Gaudí)

Considerando a tríade vitruviana, pode-se dizer que, além da função, variável histórico-cultural, a arquitetura deve contemplar forma e construção. Nos dois casos, a naturezaconstitui uma importante fonte de referência empírica. Ao longo da história da arte e daarquitetura, a natureza tanto tem emprestado suas formas para serem imitadas como oferecido padrões de organização, que, por meio de um processo de abstração, funcionam como suporte de atividades compositivas e construtivas.

Tendo o homem como medida-padrão e considerando os seres humanos capazes de refletir harmonia e beleza, no período clássico, a relação entre natureza, arte e arquitetura expressou-se de modos distintos. Como universo a ser imitado, foi base paraa criação de esculturas, por exemplo as cariátides, pilares, quase sempre em formas defiguras femininas, de sustentação dos entablamentos. Presente nas espirais do crescimento natural e considerada divina, a Seção Áurea foi referência, por exemplo, para a determinação das dimensões das fachadas dos templos gregos; e também das relações entre distância, diâmetro e altura de suas colunas. No primeiro caso, bastou a simples observação; no segundo; foi necessário o domínio de um corpo de conhecimento abstrato para possibilitar a representação dos padrões encontrados e a solução de problemas deles decorrentes.

Se na arquitetura barroca e rococó os elementos orgânicos serviram como 
motivos decorativos, no gótico, prevaleceu uma atitude especulativa em relação à lógica estrutural oculta na natureza.

A arquitetura de Gaudí, um estudioso do gótico, também exprime formas diferenciadas de relação com a natureza: com base na simples observação, projetou vários elementosinspirados diretamente na natureza. Aprofundando o estudo da natureza, identificou nasestruturas orgânicas fibras retas que davam origem a superfícies curvas - helicóides, hiperbolóides e parabolóides. E, com base nisso, desenvolveu a teoria da geometria regrada, a partir da qual produziu uma arquitetura surpreendente e inovadora.

No século XX, a necessidade de 'desenhar para as máquinas', com vista à produção em massa, implicou uma busca pela essência, com ênfase na ortogonalidade, na expressão clara de uma geometria euclidiana, capaz de se traduzir em um racionalismode caráter universal.

Em um esforço de racionalização e criação de proporções harmônicas, Le Corbusier, voltando ao cânone grego da Seção Áurea, concebeu, em 1948, o Modulor (module + section d'or), baseado no raciocínio matemático e nas dimensões humanas. Além da arquitetura clássica, Le Corbusier se inspirou na arquitetura vernacular e nas "obras" da natureza, que, segundo ele, é "extremamente simples e economicamente bela".

Com os mais recentes avanços da tecnologia, criaram-se novas possibilidades de construir edifícios, formalmente mais sofisticados, inspirados em padrões orgânicos, como, por exemplo, alguns exemplares da obra de Santiago Calatrava. Em alguns destes, existe uma analogia direta com a natureza, em outros, o processo de abstraçãoé menos sumário, como no caso do Turning Torso, construído em Malmo, na Suécia entre 2001 e 2005.

Acredito que a geometria seja fundamental para entender arquitetura. Meu trabalho é feito por meio da geometria. No mundo da arquitetura, a linguagem geométrica é tão importante quanto a linguagem estrutural (Calatrava, 2002, p. 63).

\subsection{LENDO A NATUREZA}

A arte não reproduz o visível, mas torna visível. A essência da arte gráfica conduzfacilmente e, com toda razão, para a abstração. (Paul Klee)

Considerando a natureza um importante ponto de partida para o ensino de 
disciplinas preparatórias para o projeto arquitetônico e descartando a mera reprodução ou imitação de seus 'objetos', defende-se um processo pedagógico que, iniciado pela análise das formas, abra espaço para um esforço de abstração capaz de transformá-las em elementos próprios do vocabulário arquitetônico. Trata-se de se apropriar da geometria das formas orgânicas, em prol do enriquecimento do repertório a ser usado no projeto.

O desafio inicial é, sem dúvida, o registro empírico por meio do desenho de observação. Em que pese o fator interpretativo, essa atividade constitui o primeiro passo da fase analítica da natureza.

[...] o ensino do desenho para os adolescentes visa desenvolver o hábito da observação, o espírito de análise, o gosto pela precisão, fornecendo-lhes meios de traduzirem ideias e de os predispor para as tarefas da vida prática, concorrerátambém para dar a todos uma melhor compreensão do mundo das formas que nos cercam, do que resultará uma identificação maior com ele. (Costa, 1995, p. 242)

Em seguida parte-se para uma segunda etapa, que corresponde à geometrização das formas orgânicas registradas pela observação. Seguindo Cézanne ao propor "[...] tratara natureza conforme o cilindro, a esfera, o cone", busca-se identificar, nos 'objetos' estudados, sua geometria, suas características e as relações entre elas. Registram-se ainda, os ritmos decorrentes da repetição de elementos, ou seja, os padrões de ordempor meio dos quais a natureza é disciplinada.

[...] a natureza não é caótica e atomizada. Seus padrões são primários e inerentese a ordem fundamental de beleza é aparente. Mas a beleza sugere mais que umasimples ordenação, especifica um tipo particular de ordenação: postula a ordem compatível com a singularidade [...] É esse preceito que nós percebemos como beleza. (Weiss, 1960, s.n.)

De investigador atento, avança-se para a condição de intérprete, que deve desvendar acomplexidade formal explícita nos sistemas do mundo natural e, também, por meio de um processo analógico-dedutivo, trazer à tona os padrões geométricos que habitam o campo do invisível.

Esse esforço é precedido por um arcabouço teórico sobre abstração. Por meio de aulasexpositivas, busca-se conscientizar os alunos que, apesar de a 
motivação intuitiva paraa abstração ser tão antiga quanto a civilização, o advento da arte abstrata como um movimento de vanguarda se deu em função de condições sociais, políticas e culturais determinadas.

\subsection{DESCOBRINDO O ABSTRATO}

A motivação para a abstração pode ter surgido, para o homem pré-histórico, como umfator de repouso diante das arbitrariedades dos fenômenos naturais, e devido à necessidade de construir símbolos.

A felicidade que procuravam na arte não consistia em mergulharem nas coisas do mundo exterior ou nele se deleitarem, mas em retirar o objeto individual desua contingência arbitrária e aparente e torná-lo eterno pela aproximação às formas abstratas e, assim, encontrar um lugar de repouso na fuga dosfenômenos. (Worringer apud Jung, 2008, p. 307)

Com base nos registros nas cavernas espanholas de El Castillo e La Garma, o arqueólogo Paulo Pettit comentou:

[...] as imagens sugerem que a arte mais antiga era não figurativa, podendo ter implicações significativas no modo como a arte evoluiu", e acrescentou "Isso sugere que um período prolongado de arte geométrica ou abstrata [...] tanto na África como na Europa, precedeu o surgimento de representações figurativas. (The Telegraph, 30 de outubro de 2014)

Apesar do instinto de resumir os objetos à sua essência ter sido experimentada desde os povos ancestrais e poder ser observada nas representações infantis, muitos séculos se passaram antes que a arte abstrata fosse institucionalizada como um movimento artístico coletivo e consciente.

Entre os eventos que contribuíram para isso, estão: a Revolução Industrial; o surgimento e popularização da fotografia; o advento da aviação, simbolicamente representado pelo voo do 14-Bis (1906), de Santos Dummont; a Primeira Guerra (1914-1919); a Revolução Bolchevique (1917). E ainda a publicação de obras como:A Origem das Espécies (1859) e A Descendência do Homem (1871), de Charles Darwin; O Capital (1867), de Karl Marx; A Interpretação dos Sonhos (1899), de Sigmund Freud; e A Teoria da Relatividade (1912), de Albert Einstein.

A Revolução Industrial deixou suas marcas: as máquinas e 0 desenvolvimento das pesquisas científicas e tecnológicas traçaram as bases da modernidade na qual a arteabstrata fincou os seus estatutos. 
Se de início considerava a máquina um "mal absoluto", Morris, em seus últimos pronunciamentos, mudou o tom, chegando a afirmar que devíamos "tentar ser senhores de nossas máquinas e usá-las como instrumentos para conseguir melhorescondições de vida". (2012, p. 335-336)

A economia política marxista havia seduzido muitos intelectuais, fazendoos acreditarque não se tratava simplesmente da produção de um novo design, ou de uma nova arte, mas da possível emergência de um novo homem que, fruto do progresso industrial, deveria dominá-la em nome de uma nova realidade políticoeconômica.

Paralelamente, a ampla divulgação da teoria darwinista fez aumentar as idas de expedições científicas para a África. Embora para a maioria dos viajantes o valor estético da cultura material das colônias africanas não estivesse em primeiro plano, os objetos trazidos para os emergentes museus europeus chamaram a atenção dos artistas locais, preocupados com a produção de uma nova arte. Assim, ao mesmo tempo em que a Europa se apoiava no evolucionismo para impor sua cultura aos territórios em processo de colonização, os artistas utilizavam-se das culturas africanas como contraponto valores da burguesa européia considerada então decadente.

Renegando os cânones da arte alemã e afirmando a necessidade de buscar as causas das emoções, os artistas ligados ao Die Brücke (A Ponte) Kirchner,Pechstein, Keckel -, por exemplo, substituíam a representação do rosto humano pelaexpressão das máscaras africanas. Picasso, ao pintar o primeiro quadro cubista, As Senhoritas de Avignon, também fez referências a essas máscaras.

Além disso, o advento da fotografia retirou da arte a missão de registrar a natureza com realismo, colocando em discussão os valores e os significados das imagens produzidas pela pintura e pela fotografia.

[...] a fotografia ajudou os pintores 'de visão' a conhecer sua verdadeira tradição, ajudou-os a separar, nas obras dos grandes mestres, os puros fatosde visão de outros componentes culturais que, até então, haviam impedido deavaliar essas obras do ponto de vista da pesquisa sobre a visão. (Argan, 1992,p. 81)

O advento do avião, por sua vez, possibilitou o descortinar de novos ângulos de visão. Para Dubois, definia-se um modo de percepção e representação do 
espaço diferentedaquele herdado da perspectiva monocular clássica, ou seja, um novo tipo de relaçãoentre o sujeito e o mundo.

Na obra de Le Corbusier, que celebrou a importância da conquista dos ares para a arquitetura e o urbanismo, o avião adquiriu diferentes formas e significados. O desnudar novas perspectivas permitiu ao arquiteto ver e conceber a cidade a partir doalto, como uma grande maquete, em uma 'promenade architecturale', dando ensejo à criação de novas possibilidades urbanísticas.

A arte tornava-se também devedora de um novo olhar, que não a do caminhante, ou a do pássaro a que se referiu Le Corbusier. A 'visão' do inconsciente do artista também passava a ser levada em conta. A psicanálise, método que se mostrava capaz de evidenciar o significado inconsciente das palavras, ações e produções imaginárias do sujeito, exerceu influências decisivas sobre a criação artística, ao mesmo tempo em que foi por ela influenciada. Para Freud, o estado psíquiconecessário para realização da análise dos sonhos, na qual o indivíduo renuncia à crítica da censura, é semelhante à condição necessária para a criação artística. Ao afirmar que este conseguia expor as fantasias acumuladas em seu inconsciente, provocando uma reação em cadeia no espectador, o pai da psicanálise reafirmou o caráter libertador da arte.

Na mesma época, as descobertas de Einstein despertavam curiosidade mesmo entreos cidadãos comuns. A explicação para que conceitos científicos de difícil compreensão atraíssem tão amplo interesse poderia estar no clima de efervescênciacultural da época, decorrente das inúmeras invenções científicas e tecnológica, que transformavam radicalmente a vida de todos e seduziam artistas e intelectuais.

As vanguardas históricas logo se dispuseram a contemplar, em suas obras, a nova relação espaço tempo. Monet, por exemplo, realizou vários quadros repetindo 0

motivo e mudando o instante em que os pintava, na tentativa de incorporar o tempo ao espaço da tela.

As pinturas cubistas, por sua vez, ao exibirem simultaneamente diferentes perspectivas de um mesmo objeto, constituem verdadeiros exemplos de representações quadridimensionais, isto é, de relações espaço-tempo.

Os pintores foram levados com naturalidade e por intuição a se 
preocuparemcom as novas possibilidades de medida do espaço [...] a quarta dimensão representa a imensidade do espaço eternizando-se em todas as direções, emum momento determinado. É o próprio espaço, a dimensão do infinito. (Apollinaire, 1997, p. 17-18)

Nos anos que precederam à Primeira Guerra, a crise da cultura europeia e o tédio emrelação à arte acadêmica conduziram a uma necessidade de ruptura com a tradição, contribuindo para direcionar os olhares para uma arte completamente inovadora. Segundo Silver (1989), os espectros da guerra exerceram uma influência direta sobrea arte do período. Chamando a atenção para a similaridade entre o discurso dos analistas políticos e o de vários artistas e críticos de cultura, observou que os termose as concepções, que sustentavam as ideias de 'chamado à ordem' e 'reconstrução' na França do pós-guerra ecoavam nos escritos e declarações dos artistas, incorporando-se à sua arte.

$\mathrm{Na}$ época, os artistas foram seduzidos também pelas ideias da chamada vanguarda russa, que havia emergido com a Revolução Bolchevique de 1917. Os discursos revolucionários dos construtivistas contribuíram para reforçar, no imaginário europeu, a necessidade de produzir uma arte nova. Ao negar quaisquer influências históricas, os artistas soviéticos, preocupados com a construção de uma nova simbologia, viam na arte abstrata um importante instrumento de renovação e transformação social.

lém de destacar a arte e arquitetura como produtos diretos de determinada cultura, esta breve reflexão visa conscientizar os alunos sobre o compromisso dos artistas e arquitetos com a transformação do mundo em que vivem.

Entra em cena então a geometria. Pontos, linhas retas e curvas, triângulos, quadrados,círculos, espirais etc. tornam-se códigos para o registro dos padrões da natureza. Ao invés de tratar a geometria como um fim em si mesmo, propõese que o desenho geométrico se dê ao longo do processo analítico, na medida em que surgem as necessidades de reconhecimento e representação das diferentes formas.

Os entes geométricos básicos passam a ser estudados em suas possibilidades e variedades: compõem-se linhas com pontos, planos com linhas e volumes com planos.Como disse Kandinsky, "Devemos, de início, distinguir os elementos básicos - pontos, linhas, planos - sem os quais uma obra não pode 
sequer chegar a existir" (1996, p. 30).

A rigor, as formas geométricas são puros entes mentais que registramos, valendo-nos do desenho [...] E, a palavra "desenho" resulta, em seu profundo significado linguístico, altamente reveladora, porque mediante o desenho traçamse sinais, ou seja, símbolos. (Colerus, 1952, s.n.)

\subsection{VIVENCIANDO O LÚDICO}

É libertando seu espírito lúdico e buscando atingir a beleza que o homem dá vazão aoprocesso de criação.

O lúdico constitui uma categoria absolutamente primária da vida, tão essencial quantoo raciocínio (homo sapiens) e a fabricação dos objetos (homo farber). O homem que brinca não substitui o homo sapiens, mas se coloca ao lado e um pouco abaixo deste, mais ou menos na mesma categoria que o homo farber. (Huizinga, 2000)

As brincadeiras exigem sempre muita concentração. Desconectar-se da realidade cotidiana e mergulhar em um mundo paralelo é algo natural e prazeroso, que faz parteda vida infantil. "As crianças e os animais brincam porque gostam de brincar, e é precisamente em tal fato que reside sua liberdade" (Huizinga, 2000, p. 5), e talvez suaforma mais eficaz de aprendizagem.

Em geral, quanto mais abstrato é brinquedo, melhor para ativar a criatividade. Na imaginação da criança, um mesmo objeto pode ter diferentes significados: galhos podem ser espadas, caixas de papelão transformam-se em carrinhos ou casinhas e lençóis podem abrigar vários seres e mundos utópicos. Ao brincar, o espírito salta entre a matéria e as coisas pensadas e a imaginação pode se expressar por meio de diferentes linguagens.

Em suas garatujas iniciais, a criança tem dificuldade de usar diagonais ou triângulos. Após o domínio dos movimentos circulares dos seus braços e pulsos, surge o desenhodo círculo como primeiro objeto fechado. Depois, a criança passa a representar o dentro e o fora, o fechado e o aberto. Mais tarde, somar-se-ão aos círculos as retas horizontais e verticais, que irão compor os desenhos lúdicos e criativos do universo infantil.

A criança não desenha o que vê, mas o que sente. Com poucos traços, registra a essência do momento e do objeto com o qual se relaciona durante o ato criativo. Geralmente, enquanto preenche as folhas de papel, fala, canta ou 
murmura sons relativos às estórias que conta em seu desenho.

Temos muito que aprender observando os jogos infantis, nos quais prazer e seriedadenão são excludentes, podendo-se fazer algo sério também por diversão. Infelizmente, parece que, ao crescer, o homem perde essa capacidade de se libertar e de abstrair facilmente percebida nas brincadeiras infantis.

Alguns artistas tinham consciência de que atingiriam o auge criativo quando resgatassem seu espírito lúdico, ou quando voltassem a pensar como crianças. Sobreisso, Picasso afirmou: "Quando eu tinha 15 anos, sabia desenhar como Raphael, masprecisei uma vida inteira para desenhar como criança." (apud Vasconcellos, 2007, p. 102)

Até aceitar como finalizada sua criação, Picasso desenhou inúmeras vezes a imagemdo touro, animal bastante significativo da cultura catalã, buscando sua essência.

Além de Picasso, outros artistas de vanguarda tentaram ampliar os limites da arte figurativa, e, para tanto, incorporaram ao seu processo criativo o exercício da abstração. Miró, por exemplo, cujos "[...] olhos eram como os de uma criança que vê uma coisa que a entusiasma", reinventou uma representação do mundo: "[...] suas figuras, mulheres, estrelas e pássaros, são como letras, fazem parte de um alfabeto que ele vai construindo até o fim" (Peiró, 2014) ${ }^{1}$. Calder, por sua vez, inspirado em brinquedos e animais, produziu objetos com qualidades intelectuais e artísticas, mas,sobretudo, lúdicas e, por isso, emocionais.

Movido por uma paixão pela música e pelo forte interesse pelos sonhos e pelas incongruências do subconsciente, Paul Klee combinou inocência e sofisticação. Suasobras refletem seu humor seco, sua visão infantil, suas crenças pessoais e sua musicalidade.

Rosário Peiró é Chefe do Departamento de Coleções do Museu Rainha Sofia.

Exemplos de processos de abstração, que podem ser encontrados, de modo bastanteexplícito, na obra de Piet Mondrian, Theo van Doesburg entre outros, integram o conjunto de referências para os trabalhos a serem desenvolvidos pelos alunos.

Durante o processo de decomposição, desvendam-se, além das relações entre as formas, suas características estruturais e/ou expressivas. Enquanto os 
volumes remetem a peso ou massa; os planos, 'peles', mais leves, indicam mais leveza; as linhas, por sua vez, podem ser responsáveis pela resistência, enquanto os pontos funcionam como 'nós', ou locus de amarração estrutural.

O reconhecimento das características superficiais dos objetos da natureza configura uma importante experiência tátil-visual. Além das cores, a conscientização sobre as diferentes texturas, como liso, rugoso, áspero, brilhante, opaco etc., contribui tanto parao aumento do repertório formal como, sobretudo, para o refinamento da capacidade sensorial.

\subsection{REINVENTANDO A NATUREZA}

A natureza é pródiga na provisão de elementos que a fantasia humana pretende recombinar livremente criando novos padrões de sua própria criação. (Weiss, 1960, s.n.)

[...] ao formar, ao dar forma à imagem, o artista é obrigado a deformar. Por necessidade substituirá as formas existentes na natureza por outras. [...] Mesmo querendo inspirar-se em formas da natureza, o artista as abandona para criar formas de linguagem. (Ostrower, 1991, p. 310)

De posse de um vocabulário e uma gramática formal adquiridos nas fases analítica e interpretativa, chega a hora da síntese do processo de aprendizado, ou seja, o momentode escrever o poema plástico, de buscar o lirismo das formas, de construir uma linguagem artística. Como seres eminentemente criadores, e motivados pelos exercícios anteriores, os estudantes partem para a concepção de objetos bi- e tridimensionais cuja única função é criar beleza. Como disse Oscar Niemeyer, "Quando uma forma cria beleza, tem na beleza a sua própria justificativa".

Ao reforçar o caráter da arquitetura enquanto arte trata-se de concebê-la como criação, mas também como construção, o que impõe o desafio de fazer com que as composições, além de bidimensionais, expressas por em desenhos e colagens etc., também se tornem tridimensionais, por meio da confecção de protótipos e modelos.

Por outro lado, considerando que a arte é um produto da cultura, cabe analisar as diversas interpretações feitas pelos muitos artistas historicamente consagrados. As aulas, com exposição e discussão de obras bi e tridimensionais - pinturas, gravuras, colagens, esculturas, instalações etc., contribuem para 
ampliar ainda mais o repertório; conscientizar sobre a construção dessas formas; e tornar mais transparente a lógica portrás do ato criativo. Um breve passeio pela história da arte moderna ilustra como um deles fez uso dos recursos ou valores plásticos para expressar sua visão de mundo, suaarte. No século $X X$, conscientes das descobertas sobre a percepção humana, muitos artistas, utilizando as distorções inerentes ao sentido da visão, buscaram estabelecer um diálogo lúdico com o observador.

Assim sendo, informações sobre as teorias da Gestalt e das Cores complementam o arcabouço teórico e preparam os alunos para a apreciação das obras de arte, que vão do impressionismo e pontilhismo, passando neoplasticismo, suprematismo, op-art, até chegar à contemporaneidade. Merecem destaque as criações da vanguarda brasileira integrante dos movimentos Concreto (Grupo Ruptura), de São Paulo, e Neoconcreto (Grupo Frente), do Rio de janeiro, entre as décadas de 1950 e 1960.

Além dos valores compositivos, como equilíbrio, simetria, contraste, unidade, harmonia, proporção, cor, figura-fundo etc., trata-se de evidenciar o movimento e o ritmo como propriedades inerentes à composição plástica moderna.

Constantemente impactada por uma grande quantidade de informações e imagens, em uma sociedade do descartável e das rápidas mutações, a nova geração tende, em geral, a apresentar baixa capacidade de concentração. Assim sendo, as aulas expositivas sãodadas sempre após o início do trabalho criativo, pois, como já foi constatado, o aproveitamento é tanto maior quanto mais os alunos estiverem conscientes dos problemas e envolvidos com a busca de soluções.

Depois de concluídos os estudos, são discutidas as alternativas para a arte final das composições bidimensionais, sendo que a escolha das cores se dá por meio da experimentação, da tentativa e erro. Esses exercícios servem tanto para familiarizar os alunos com os diferentes materiais e técnicas como para desenvolver a coordenação motora fina, já que as artes visuais não têm sido devidamente contempladas nos ensinos fundamental e médio brasileiros.

No caso dos trabalhos tridimensionais, depois das ideias iniciais dos alunos, os protótipos, em tamanho real, são avaliados segundo as possibilidades 
e alternativas dematerialização, sendo que, muitas vezes, devido à inexistência de uma oficina

apropriada na FAU-UnB, é necessária a colaboração de profissionais externos -marceneiros, serralheiro etc. - para a execução final.

\section{CONSTRUINDO FANTASIAS}

A utopia está lá no horizonte. Me aproximo dois passos, ela se afasta dois passos. Caminho dez passos e o horizonte corre dez passos. Por mais que eu caminhe, jamais alcançarei. Para que serve a utopia? Serve para isso: para que eu não deixe de caminhar. (Eduardo Galeano, apud Heck, 2015)

Com um repertório compositivo mais consolidado, torna-se possível dar asas à imaginação e se aventurar pelo campo da criação mais liberta. Surgem, então, as fantasias... manifestações do espírito que, emergindo dos cérebros criativos, impregnam, por meio da construção de objetos plásticos, a realidade do nosso espaço vital.

Sentimentos como tristeza, alegria, dor, prazer concorrem para estimular o sensível e osubjetivo de cada um, fazendo desencadear um processo de criação capaz de associara dimensão puramente racional com os insights do inconsciente. Os estados ocultos doespírito criativo, depois de transformados (ou sintetizados) em símbolos visuais, são transpostos para o campo do real.

A partir da observação e do registro de manifestações culturais - como a dança, o circo,o carnaval -, ou de seus personagens, são desenvolvidos trabalhos de criação em duase três dimensões. Pinturas, colagens e esculturas materializam releituras inéditasdesses eventos, que, fazendo parte do patrimônio imaterial, têm o corpo humano comoprincipal desafio compositivo.

O desafio do processo de abstração nesse caso é preservar a identidade do tema proposto para o exercício, de modo que o espectador consiga reconhecêlo. Para isso, enquanto os produtos derivados de elementos da natureza indicam predominantemente um abstracionismo geométrico, os resultantes das manifestações culturais expressam um abstracionismo lírico, mais adequado ao resgate do significado e do simbólico de tais manifestações e de seus personagens emblemáticos.

Ainda na etapa da construção de fantasias, cabe destacar as experiências 
pedagógicasrealizadas sobre a temática urbana.

\subsection{MERGULHANDO NO REINO DAS UTOPIAS}

Embora seja sua função projetar edifícios para as diferentes funções da sociedade daqual fazem parte, os arquitetos não devem perder a perspectiva de participar da transformação da realidade. É sonhando com um mundo mais justo e um homem mais fraterno que, desenhando utopias, eles podem construir o seu mais importante legado. Afinal, "a gente tem que sonhar, senão as coisas não acontecem " (Oscar Niemeyer).

Utopia (do grego oủ 'não' + tómos, 'lugar'), 'não-lugar' ou 'lugar inexistente', deu nomeà obra de Thomas Morus de 1516, que descreve um lugar novo e puro onde existiriauma sociedade perfeita.

Apesar de não terem sido implantados, muitos projetos utópicos serviram de inspiração para propostas futuras inovadoras e, por isso, constituem importantes documentos da história da arquitetura, como a Città Nuova (1912) uma megalópolecom arranha-céus, passarelas e vias suspensas -idealizada por Antonio Saint'Elia.

Após a revolução Bolchevique de 1917, muitos planos de edifícios e cidades, concebidos por arquitetos vinculados ao Construtivismo soviético, exerceram uma significativa influência no mundo ocidental. Por nunca terem sido construídos, esses estudos ficaram conhecidos como 'arquiteturas de papel'.

O movimento, que se desenvolveu em torno dos princípios defendidos no Congressolnternacional da Arquitetura Moderna (CIAM), em 1928, e que teve a Carta de Atenas (1933) como seu mais importante resultado, estabeleceu diretrizes para os espaços do futuro a serem ocupadas pelo novo homem. Considerando a cidade um organismofuncional, Le Corbusier desenvolveu, entre outras propostas, a Ville Contemporaine (1922), que, capaz de abrigar três milhões de habitantes, deveria responder aos desafios impostos pelo crescimento populacional e pelo adensamento urbano.

A essa iniciativa utópica, outras se seguiram nas décadas seguintes.

O Manifesto Internacional Situacionista (1960), lançado por uma vanguarda liderada por Guy Debord, pretendia a quebra das formas vigentes de arte, cultura e organização social.

O pensamento utópico do grupo ficou imortalizado no projeto, desenvolvido 
pelo arquiteto Constant Nieuwenhuys, New Babylon (1959-1974), uma cidade tecnológicade nômades, cuja construção iria sendo feita à medida que a população se deslocassesobre as existentes. Para ele, o homo ludens substituiria o homo farber.

O movimento Metabolista, formado por um grupo de arquitetos japoneses liderados por Kenzo Tange, previa que a cidade do futuro seria habitada por uma sociedade de massas, caracterizada pela grande escala, pelas estruturas flexíveis cujo crescimento seria similar ao orgânico.

Em 1963, o grupo Archigram, integrado por arquitetos ingleses, desenvolveu propostas hipotéticas, que buscavam um diálogo com o efervescente contexto culturalda época. A ideia era representar inovações arquitetônicas que, subvertendo o sistema dominante, pudessem alterar o modus vivendi.

No final da década de 1960, o Superstudio, criado pelos arquitetos italianos Adolfo Natalini e Cristiano Toraldo, desenvolveu o Monumento Contínuo, uma estrutura capaz de cruzar e circundar o mundo, vencendo os desafios de qualquer território. Por meio da justaposição de cidade e natureza, estabelecia um novo layer, preservando os edifícios existentes.

Todas essas propostas, que têm influenciado a arquitetura contemporânea, servem como objeto de reflexão e estímulo para o desencadeamento de propostas urbanas mais ousadas e inovadoras.

\subsection{IMAGINANDO CIDADES INVISÍVEIS}

Além de exercícios com base em cidades reais, são feitas interpretações e composiçõessobre As Cidades Invisíveis (1972), descritas na intrigante obra de Italo Calvino. Neste caso, embora o ponto de partida seja a cidade que cada um tem dentro de si, são incentivados os sonhos, os voos em direção às utopias, como forma de neutralizar a tendência de reproduzir estereótipos que, decorrentes da globalização e da especulação imobiliária, têm tornado as metrópoles contemporâneas cada vez mais semelhantes entre si.

O catálogo de formas é interminável: enquanto cada forma não encontra sua cidade, novas cidades continuarão a surgir. Nos lugares em que as formas se exaurem as suas variedades e se desfazem, começa o fim das cidades. Nos últimos mapas do atlas, diluíam-se retículos sem início nem fim, cidades com a forma de Los Angeles, com a forma de Kioto, Osaka, sem forma. (Calvino, 1991, 
p. 126)

A intenção não é reproduzir o visível ou o existente, mas, entender as cidades como organismos únicos e dinâmicos que, enquanto seres vivos, absorvem e produzem sensações, sendo, portanto, impossíveis de serem copiadas ou sequer apreendidas emsua totalidade.

Como a diferença entre o exercício a partir de cidades reais e o das cidades invisíveisé justamente o caráter utópico destas últimas, foram pensadas aulas para que os alunos, saindo da 'zona de conforto', acreditassem na possibilidade de inventar o inexistente, o inusitado.

Para incentivar a atualidade das propostas dos alunos, além da produção artística historicamente consagrada, são mostrados desenhos e protótipos de jovens artistas, e também dos estudantes de respeitáveis escolas de arte e arquitetura.

\section{4 À GUISA DE CONCLUSÃO}

Mais espaço houvesse, mais poderia ser dito sobre as experiências pedagógicas cujo pressuposto é o espírito lúdico, que usa a abstração como ferramenta para construçãode utopias. Tida frequentemente como hermética, a geometria torna-se brincadeira paraos que dela se apropriam e agradável para aqueles que a observam.

Cada resultado parcial constitui um experimento e um produto, configurando uma estratégia que, valorizando ambos, tem, no primeiro, o estímulo à criação e, no segundo, a oportunidade de comunicação das criações resultantes. À ebulição cerebral própria do ato criativo contrapõe-se o fazer manual, que resgata o equilíbrio psíquico, desenvolve a coordenação motora fina e estimula a aprendizagem.

Considerando que o arquiteto deve ter um compromisso com os horizontes futuros, ao acolher ordem e geometria como meios, pretende-se, como fim, conduzir o processo deaprendizado a um avanço no campo da liberdade plástica, da criatividade, enfim, da construção de fantasias. 


\section{REFERÊNCIAS}

Lei n. 12.881, de 12 de novembro de 2013 (2013). Dispõe sobre a definição, qualificação, prerrogativas e finalidades das instituições comunitárias de educação superior - ices, disciplina o termo de parceria e dá outras providências. Brasília, df. Recuperado de https://www2.camara.leg.br/legin/fed/lei/2013/lei12881-12-novembro-2013-777421-publicacaooriginal-141829-pl.html

Relatório balanço social (2019). Responsabilidade social. Criciúma, sc. Recuperado de http://www.unesc.net/portal/resources/official_documents/18920.pdf?160098206

Schmidt, j. P. (org.) (2009). Instituições comunitárias: instituições públicas nãoestatais. Santa cruz do sul, rs: edunisc. 